\title{
openheart Cardiovascular drugs attenuated myocardial resistance against ischaemia- induced and reperfusion-induced injury in a rat model of repetitive occlusion
}

To cite: Gatzke N, Güc N, Hillmeister $\mathrm{P}$, et al.

Cardiovascular drugs attenuated myocardial resistance against ischaemia-induced and reperfusion-induced injury in a rat model of repetitive occlusion. Open Heart 2018;5:e000889. doi:10.1136/ openhrt-2018-000889

Received 29 June 2018 Revised 3 October 2018 Accepted 12 November 2018

D) Check for updates

(C) Author(s) (or their employer(s)) 2018. Re-use permitted under CC BY-NC. No commercial re-use. See rights and permissions. Published by BMJ.

${ }^{1}$ Department for Angiology, Brandenburg Medical School, Campus Brandenburg/Havel, Brandenburg, Germany 2Department of Cardiology, Charité University Hospital, Campus Virchow, Center for Cardiovascular Research (CCR) Charité University Hospital, Berlin, Germany

${ }^{3}$ Department of Cell and Developmental Biology \& Institute for Toxicology and Genetics, Karlsruhe Institute of Technology, Karlsruhe, Germany ${ }^{4}$ Institute for Pharmacology and Preventive Medicine, Cloppenburg, Germany

Correspondence to Dr Ivo R Buschmann; buschmann@dazb.de

\section{ABSTRACT}

Objective We investigated the impact of cardioprotective drugs on ST-elevation, arrhythmias and infarct size in a rat model of repetitive coronary artery occlusion.

Methods Seventy Sprague-Dawley rats were randomised to two control and five treatment groups. Placebo was either implantation of a pneumatic occluder onto the left anterior descending coronary artery (LAD) without starting repetitive occlusion (SHAM) or subsequent $R 0$ of the LAD over 10 days without medication (ROP). Treatment groups underwent $\mathrm{R} 0$ and additionally received nitroglycerin (NTG), metoprolol, verapamil (VER), ranolazine (RAN) or candesartan (CAN). Two weeks after the intervention, rats underwent a single, sustained $L A D$ occlusion followed by reperfusion. To evaluate differences in cardiac resistance against myocardial ischaemia and reperfusion injury, cardiac surrogate parameters including maximal STelevation, arrhythmias and infarct size were assessed. Results Compared with sham, R0 alone and R0 plus nitroglycerin were associated with significantly lower maximal ST-elevation and percentage of infarcted myocardium (SHAM $0.12 \mathrm{mV}$, ROP $0.06 \mathrm{mV}(\mathrm{p}=0.004)$, NTG $0.05 \mathrm{mV}(\mathrm{p}=0.005)$; SHAM $16.2 \%$, ROP $6.6 \%$ $(p=0.008)$, NTG $5.9 \%(p=0.006)$. Compared with R0 alone, R0 plus RAN was accompanied by increased ST-elevation $(0.13 \mathrm{mV}, p=0.018)$ and R0 plusVER or CAN by more infarcted myocardium $(14.2 \%, p=0.004 \%$ and $15.5 \%$, $p=0.003$, respectively). Rats treated with VER, RAN or CAN tended to severe arrhythmias more frequently than those of the control groups.

Conclusions R0 led to an increased myocardial resistance against ischaemia and reperfusion injury. Concomitant administration of nitroglycerin did not affect the efficacy of R0. Cardiovascular channel or receptor blockers reduced the efficacy of RO.

\section{INTRODUCTION}

The rate of coronary artery disease (CAD) has declined during the first decade of the 21st century. ${ }^{1}$ However, myocardial infarction remains a possibly fatal consequence. Coronary collateralisation, occurring particularly in the presence of CAD with repeat episodes

\section{Key messages}

What is already known about this subject?

- Coronary collateralisation, occurring particularly in the presence of coronary artery disease (CAD), is considered protective in the case of myocardial infarction.

- Ischaemic preconditioning increases arteriogenesis in rats and rabbits.

What does this study add?

- In this study on ischaemia-induced and reperfusion-induced injury, we found that the most widely used cardioprotective drugs in CAD unfavourably impacted the cardiac outcomes in rats after ischaemic preconditioning.

How might this impact on clinical practice?

- Care should be taken in the selection of cardioprotective drugs.

- Further research in experimental and clinical settings is necessary to elucidate the impact of concomitant medication on clinical outcomes.

of angina, is considered protective in the case of myocardial infarction. Sustained perfusion of ischaemic tissue by coronary anastomoses reduces ST-elevation, fatal arrhythmias, infarct size and mortality. ${ }^{2-5}$ Therefore, therapeutic promotion as well as prevention of impairment of collateral growth and signal pathways of myocardial preconditioning may improve survival from myocardial infarction.

Collateral growth, referred to as arteriogenesis, is a physiological response to enhanced blood flow to compensate for tissue hypoxia and ischaemia. It includes proliferation and transformation of pre-existing bridging arterial vessels into functional arterial anastomoses with enlarged calibres. Arteriogenesis is benefited by a low heart rate and the absence of hypertension. ${ }^{6}$ Additionally, it is regulated by genetic predisposition. ${ }^{7}$ 
Ischaemic preconditioning induces complex signal cascades, which stimulate arteriogenesis and reduce myocardial ischaemia and reperfusion-induced injury. Stimuli such as calcium ions, reactive nitrogen species, autacoids, neurohormones and growth factors activate kinase pathways including endothelial nitric oxide synthase finally converge in mitochondria, which are necessary to provide ATP for the maintenance of cellular integrity and the prevention of cardiomyocyte death. ${ }^{89}$

Patients with CAD most frequently are treated with antianginal or antihypertensive drugs. However, little is known whether and how these medications interact with cardioprotective signal pathways and myocardial arteriogenesis. A previous study on a rat model of repetitive myocardial ischaemia showed an increased collateral-dependent flow after completion of a 10-day repetitive coronary artery occlusion (RO) protocol compared with sham treatment. ${ }^{10}$ Based on this finding, the objective of this study was to assess whether different cardiovascular medications in addition to RO affect cardiac resistance indicated by improved functional and structural cardiac outcomes.

\section{METHODS}

\section{Animal model}

In a model of repetitive myocardial ischaemia, male Sprague-Dawley rats, aged 10-12 weeks, underwent repetitive occlusion ( $\mathrm{RO})$ of the left anterior descending coronary artery (LAD) to stimulate myocardial arteriogenesis. For this purpose, a pneumatic mini-occluder was implanted under general anaesthesia and postprocedural analgesia as described before. ${ }^{10}$ RO started 3 days after implantation of the occluder onto the heart at the level of the mid to proximal LAD. RO-induced recurrent myocardial ischaemia was induced by automated compression of the LAD three times a day for 10 days. One 40 s occlusion was performed every $20 \mathrm{~min}$ for 2 hours $20 \mathrm{~min}$, followed by 5 hours $40 \mathrm{~min}$ of rest (figure 1A,B). From the second day after implantation of the occluder and, in parallel with $\mathrm{RO}$ over a period of 10 days, the animals received cardiovascular drugs or placebo.

Seventy rats were randomly allocated to five treatment and two control groups. Treatment group animals received nitroglycerin (NTG group: $17.37 \mu \mathrm{g}$ nitroglycerin twice daily), $\beta_{1}$-blockers (MET group: metoprolol $190 \mathrm{mg} /$ $\mathrm{kg}$ /day), L-type calcium-cannel blockers (VER group: verapamil $22 \mathrm{mg} / \mathrm{kg} /$ day), sodium channel blockers (RAN group: ranolazine $62 \mathrm{mg} / \mathrm{kg} /$ day) or angiotensin II type 1 receptor blockers (CAN group: candesartan 2 $\mathrm{mg} / \mathrm{kg}$ /day). Drugs were dissolved in water and applied by oral gavage using a flexible esophageal probe. Control group animals received a placebo treatment of $0.5 \mathrm{~mL}$ water once daily for 10 days in parallel with RO (ROP control group) or without RO (SHAM control group).

One day after completion of RO and 2 days after termination of treatment, a myocardial infarction was induced in all animals artificially by sustainedLAD occlusion for
$90 \mathrm{~min}$. After subsequent reperfusion for $20 \mathrm{~min}$, rats were anaesthetised and sacrificed by $\mathrm{CO}_{2}$. Subsequently, their hearts were eviscerated for structural evaluation (figure 1C).

\section{Outcome measures}

Functional outcome measures were maximal ST-segment elevation and ventricular arrhythmias according to Lown's grading during the final occlusion. Structural outcome measure was the volume fraction of the infarcted myocardium. Cardiac structural and functional outcomes were considered representative for the extent of collateralisation.

\section{Electrocardiography}

ST-segment elevation is considered a quantitative indicator of collateral function. ${ }^{56}$ It is strongly related to infarct size and mortality. Therefore, maximum ST-segment elevation within the first $30 \mathrm{~min}$ of final occlusion was determined using LabChart data analysis software (ADInstruments, Oxford, UK). Any pre-existing ST-segment elevation $30 \mathrm{~s}$ prior to final occlusion was considered as baseline.

Arrhythmias were categorised according to Lown's grading of ventricular arrhythmia: $0=$ no ventricular premature beats (VPB), I=unifocal (<30 PVB/hour), II=unifocal and frequent $(>1 / \mathrm{min}$ or $\geq 30 /$ hour $)$, IIIb=systematised ventricular extrasystoles (bigeminy), IVa $=2$ consecutive beats (couplets), IVb $=\geq 3$ consecutive beats (salvos), V=R on T. For analysis, categories were allocated to a VPB score, scaled from 1 to 7.

\section{Infarct volume}

Constant location and time of occlusion provided, infarct volume indicates directly the collateral supply. ${ }^{611}$ Volume of the infarcted myocardium was evaluated by 2,3,5-triphenyltetrazolium chloride (TTC) staining as described below.

After final sustained LAD occlusion and subsequent reperfusion for $20 \mathrm{~min}$, hearts were perfused with phosphate-buffered saline solution. Thereafter, left ventricles were frozen at $-20^{\circ} \mathrm{C}$ for $10 \mathrm{~min}$ and cut in $2 \mathrm{~mm}$ sections. Left ventricles were then incubated in TTC solution for $20 \mathrm{~min}$ at $37^{\circ} \mathrm{C}$ and transferred to $4 \%$ formalin for 15 min. Infarcted myocardium is TTC negative and therefore becomes visible as pale pink tissue. Images were taken with Canon Super Shot S70 and acquired on a Leica MZ6 microscope.

The infarct volume was calculated from the determined infarct area of every section of the sliced left ventricle, multiplied by number and thickness of the sections. Infarct volume was expressed as a percentage from the left ventricle.

\section{Statistical analysis}

Continuous variables are reported as mean \pm SD. Means are presented with their corresponding 95\% CIs. Differences between means were compared by Dunett's multiple comparison. Kruskal-Wallis test was used to 
A
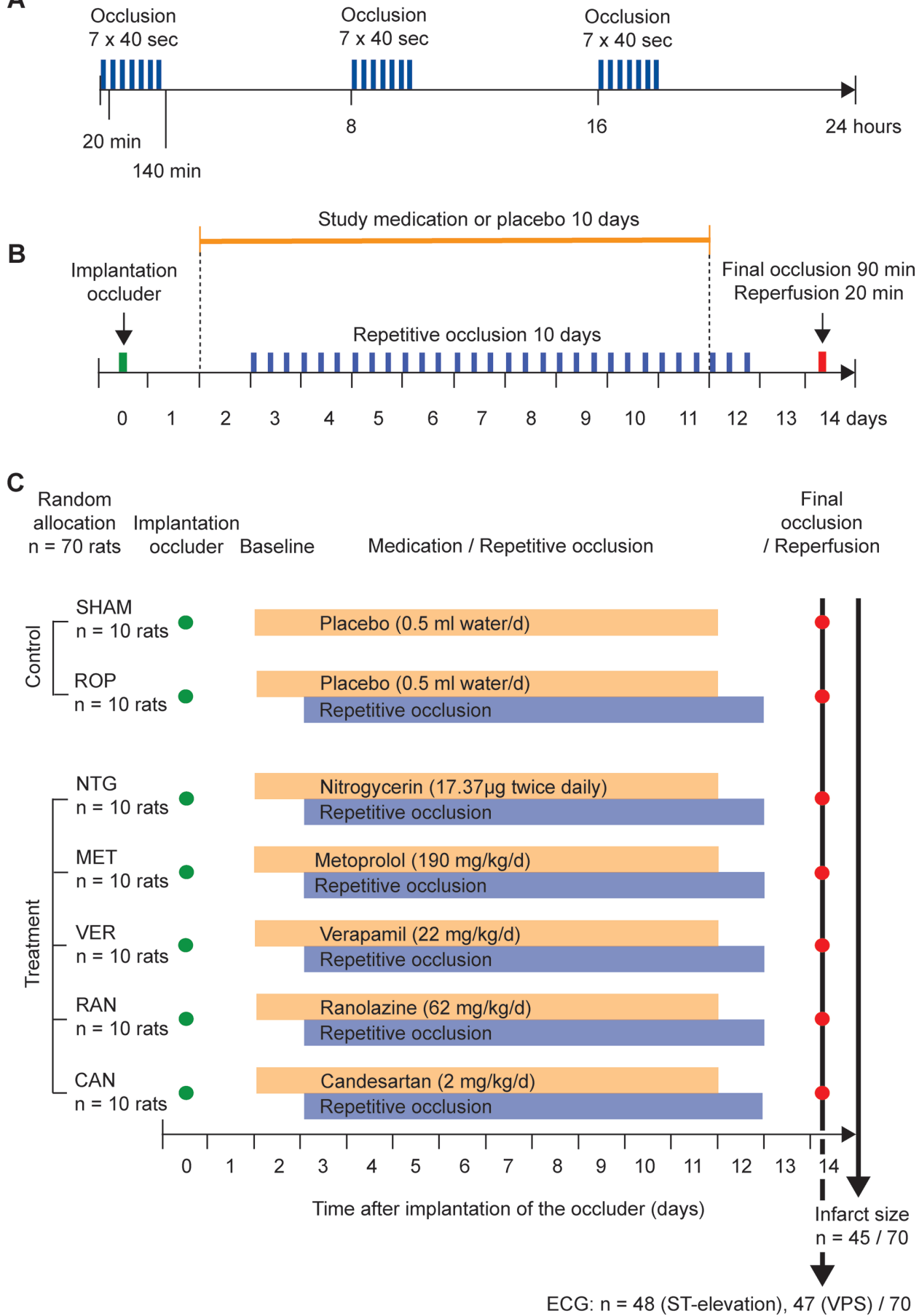

Figure 1 Study flow chart. Repetitive occlusion protocol (ROP) (A, B) and study setup (C). CAN, candesartan group; MET, metoprolol group; NTG. nitroglycerin group; RAN, ranolazine group; ROP, repetitive occlusion protocol group; SHAM, control group without repetitive occlusion; VER, verapamil group; VPS, ventricular premature beats.

compare categorical variables. A two-sided value of $\mathrm{p}<0.05$ indicated statistical significance. Statistical analyses were performed with XLSTAT software V.2015.6.01.24026 (Addinsoft SARL).

\section{RESULTS}

\section{Functional outcomes}

Maximal ST-elevation during final occlusion was significantly decreased in the ROP and the NTG group compared with SHAM. Rats treated with RO plus metoprolol, verapamil, ranolazine or candesartan did not differ significantly from SHAM but showed an increased ST-elevation compared with the ROP group. However, only the difference between the RAN and the ROP group was significant (figure 2A, table 1).

None of the treatment groups differed significantly from the SHAM or the ROP group with regard to Lown's grading of ventricular arrhythmias. However, the 


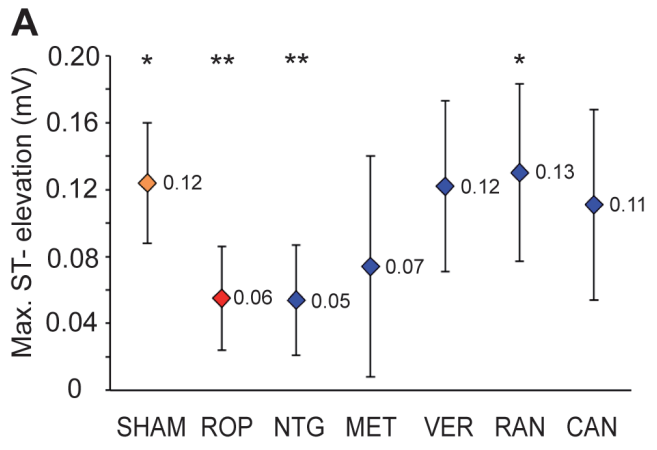

B

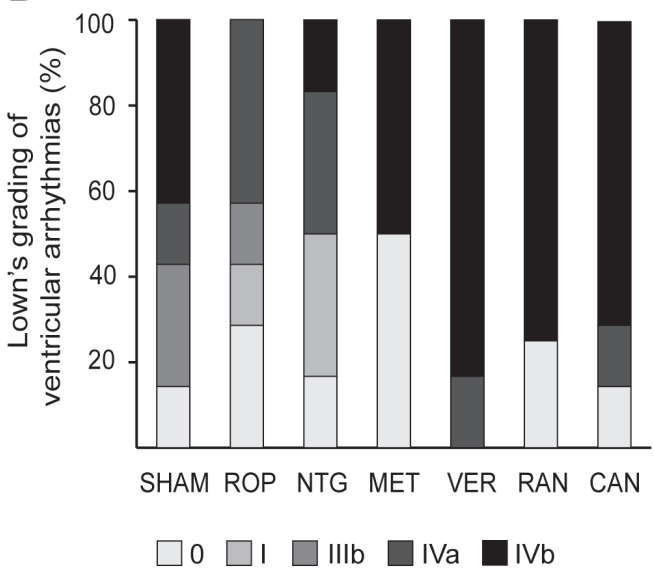

C

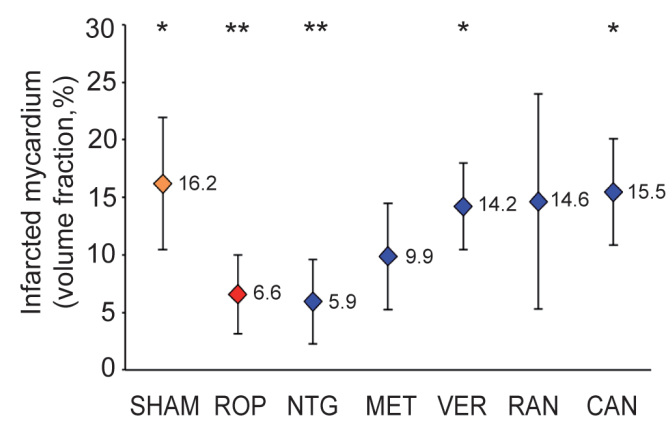

Figure 2 Effect of sustained left anterior descending coronary artery (LAD) occlusion and reperfusion on ECG findings and volume fraction of the infarcted myocardium. Maximal ST-segment elevation (A) and arrhythmias (B) were assessed during $90 \mathrm{~min}$ of final occlusion. Differences between means were compared by Dunett's multiple comparison. Means are pictured as diamonds with their corresponding $95 \% \mathrm{Cls}(\mathrm{A}, \mathrm{C})$. The Kruskall-Wallis test was used to determine whether proportions of arrhythmia grading differed significantly between each group and sham or ROP. (B). Lown's grading of arrhythmia: $0=$ no ventricular premature beats (VPB), I=unifocal ( $<30 \mathrm{PVB} /$ hour), Il=unifocal and frequent $(>1 / \mathrm{min}$ or $\geq 30 /$ hour), $\mathrm{lll} \mathrm{lb}=$ systematised ventricular extrasystoles (bigeminy), IVa $=2$ consecutive beats (couplets), $\mathrm{IVb}=\geq 3$ consecutive beats (salvos), $\mathrm{V}=\mathrm{R}$ on $\mathrm{T}$. A value of $\mathrm{p}<0.05$ indicated statistical significance versus $\mathrm{ROP}^{\star}$ or vs $\mathrm{SHAM}^{\star \star}$. Number of analysed animals is given in table 1. CAN,candesartan group; MET, metoprololgroup; NTG, nitroglycerin group; RAN, ranolazinegroup; ROP, repetitive occlusionprotocol group. ventricular premature beat (VPB) score was lowest in the ROP group. Rats treated with verapamil, ranolazine or candesartan showed a tendency to higher VPB scores (figure 2B, table 1).

\section{Structural outcome}

Percentage of infarcted myocardium by volume was significantly lower in the ROP and the NTG group compared with the SHAM. As with ST-elevation, none of the treatments increased infarct size compared with SHAM. The SHAM, VER, RAN and CAN groups showed larger infarct sizes than the ROP group with significant differences for SHAM, VER and CAN (figure 2C, table 2).

\section{DISCUSSION}

In this study on myocardial resistance in a rat model of repetitive coronary artery occlusion, we found that the most frequently used cardioprotective drugs in CAD unfavourably impacted the cardiac outcomes.

As expected, the ROP control showed improved functional and structural cardiac outcomes after sustained LAD occlusion and reperfusion compared with the sham control. Presumably, this was due to RO-induced enhanced collateralisation and thus reduced ischaemia. Additionally, RO might have served as preconditioning of reperfusion. After all, reperfusion injury accounts for up to $50 \%$ of infarct size in animal models due to oxidative stress, cell swelling, intracellular calcium overload, lactid acid washout and inflammation, all of which mediate cardiomyocyte death. ${ }^{11-15}$ However, whether repeat episodes of angina in patients with CAD similarly precondition their myocardium remains speculative.

Results after concomitant treatment with metoprolol, verapamil, ranolazine or candesartan did not differ significantly from the sham treatment, which suggests that those medications negatively affected cardioprotective signal cascades. Moreover, results from verapamil, ranolazine and candesartan tended to be worse than those from metoprolol. In contrast, RO plus nitroglycerin medication improved the cardiac outcome similar to RO alone. From this, it can be derived that nitroglycerin did not negatively affect signal transduction and arteriogenesis.

Cardioprotection including collateral growth can be achieved by different therapeutic or experimental approaches such as external counterpulsation, endurance exercise training, ${ }^{6}{ }^{16}$ administration of vascular growth factors, ${ }^{17}$ granulocyte colony-stimulating factor ${ }^{18}$ and blocking of natural inhibitors such as interferon- $\beta$ receptors. ${ }^{19}$ Therefore, one might suspect that even common cardiovascular medications for patients with CAD may affect the balance of promotion and inhibition of cardiac resistance.

\section{Nitroglycerin}

Nitroglycerin is widely administered for rapid coronary vasodilation. The active metabolite of nitroglycerin, nitric oxide (NO), is also released naturally by endothelial cells 
Table 1 Functional outcomes after cardiovascular medication in a rat model of repetitive myocardial ischaemia

\begin{tabular}{|c|c|c|c|c|c|c|c|}
\hline & SHAM & ROP & NTG & MET & VER & RAN & CAN \\
\hline Max. ST-elevation $(\mathrm{mV})^{*}$ & $\mathrm{n}=7$ & $\mathrm{n}=7$ & $\mathrm{n}=6$ & $\mathrm{n}=6$ & $\mathrm{n}=7$ & $n=8$ & $\mathrm{n}=7$ \\
\hline Mean $\pm S D$ & $0.124 \pm 0.039$ & $0.055 \pm 0.033$ & $0.054 \pm 0.031$ & $0.074 \pm 0.063$ & $0.122 \pm 0.055$ & $0.13 \pm 0.063$ & $0.111 \pm 0.062$ \\
\hline$P$ value (vs ROP) & 0.004 & - & 0.956 & 0.505 & 0.203 & 0.018 & 0.064 \\
\hline$P$ value (vs SHAM) & - & 0.004 & 0.005 & 0.114 & 0.939 & 0.832 & 0.649 \\
\hline VPB score & 4.43 & 2.86 & 3.00 & 3.00 & 5.83 & 4.50 & 5.00 \\
\hline $\mathrm{P}$ value (vs ROP) & 0.848 & - & 0.999 & 0.999 & 0.055 & 0.455 & 0.265 \\
\hline P value (vs SHAM) & - & 0.848 & 0.976 & 0.999 & 0.660 & 0.986 & 0.955 \\
\hline
\end{tabular}

*Maximal ST-elevation during 90 min of LAD occlusion.

'Ventricular arrhythmia categorised according to Lown's grading of 0 to $V$ and the associated VPS score of 1 to 7.

CAN, candesartan group; MET, metoprololgroup; NTG, nitroglycerin group; RAN, ranolazinegroup; ROP, repetitive occlusionprotocol group;

VPS, ventricular premature beats.

as a consequence of increased pulsatile, tangential fluid shear stress (FSS) within collateral vessels in the event of an upstream flow-limiting stenosis. Additionally, NO itself increases the pressure gradient and therefore, the FSS. Thus, NO leads to a flow-mediated vasodilation and additionally facilitates the cascade of vascular remodelling to activate structural modification. ${ }^{7}$ In this rat model, NO from nitroglycerin medication and naturally released NO from repetitive occlusion might have complemented, but not enhanced one another in their effect on arteriogenesis. Possibly, endogenous NO was already maximally released during $\mathrm{RO}$, analogue to results from administration of nitroglycerin during exercise. ${ }^{20}$ However, previous studies found an impaired endothelial nitric oxide synthase (NOS) pathway in elderly patients with $\mathrm{CAD}$, which goes along with decreased collateral growth. ${ }^{21}$ Therefore, nitroglycerin medication in the case of impaired nitric oxide metabolism might be an issue of further research.

\section{B-Blockers}

Beta-blockers are competitive antagonists for endogenous catecholamines and therefore lower the heart rate, which is actually considered to promote collateralisation. ${ }^{56}$ The underlying mechanism is a prolonged diastole with an increased coronary flow, followed by the upregulation of $\operatorname{NOS}^{19}$ and enhanced FSS as the main trigger of arteriogenesis. ${ }^{22}$ However, previous studies $^{23-25}$ reported on an impaired collateral flow with $\beta_{1}$ and $\beta_{2}$-blockers, probably due their vasoconstrictive effect on collaterals and the reduced oxygen demand. Additionally, $\beta_{1}$ and $\beta_{2}$-blockers were found to decrease NOS and vascular endothelial growth factors (VEGF) in embryoid bodies. ${ }^{26}$ These findings are in the line with the results of this study, which showed that metoprolol slightly impaired the effect of RO. Negative inotropic effects such as reduced extravascular compression forces, increased diastolic filling interval and improved oxygen supply by B-blockers ${ }^{27}$ might have prevented outcome from getting worse. In contrast, studies on the sinus node activity inhibitor ivabradine, which induces bradycardia without affecting myocardial contractility, showed an augmented collateral function in patients with $\mathrm{CAD}^{28}$ Moreover, the unselective $\beta$-blocker and $\alpha_{1}$-antagonist carvedilol promotes arteriolar vasodilation. It proved to be superior to metoprolol with regards to endothelial function and survival in patients with chronic heart failure. ${ }^{29}$

Table 2 Structural outcomes after cardiovascular medication in a rat model of repetitive myocardial ischaemia

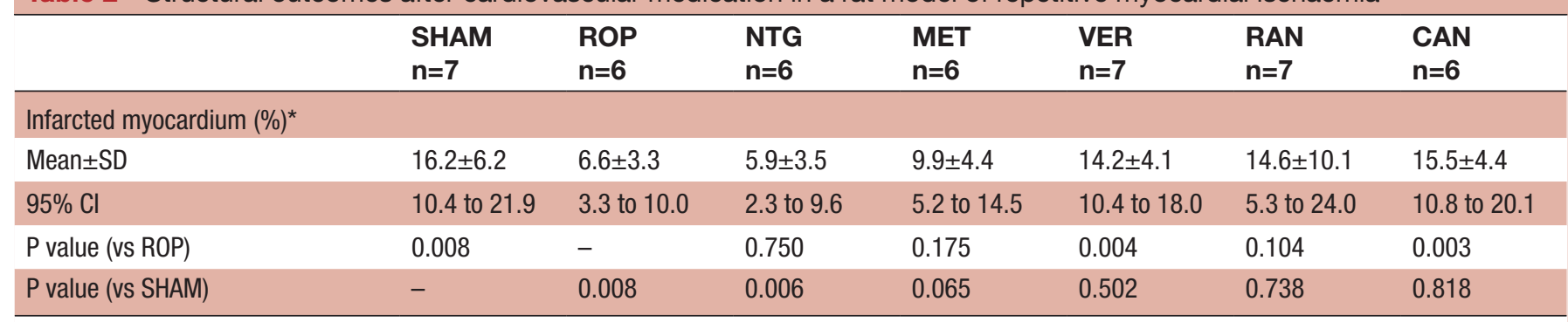

*Volume fraction of infarcted myocardium of the left ventricle after sustainedLAD occlusion and reperfusion.

CAN, candesartan group; LAD, left anterior coronary artery; MET, metoprolol group; NTG, nitroglycerin group; RAN, ranolazine group; ROP, repetitive occlusion protocol group; SHAM, control group without ROP; VER, verapamil group. 


\section{Verapamil}

Calcium-channel blockers (CCBs) are potent vasodilators. In this study, verapamil impaired the arteriogenetic effect of RO. By analogy, Kohro et al found a deleterious effect of CCBs regarding cardiovascular events in patients presenting with myocardial infarction during a 3-year follow-up. ${ }^{30}$ One possible explanation might be a coronary steal from microvascular vasodilation. ${ }^{31}$ The blood flow is drained away from the collateral-dependent ischaemic myocardium accompanied by a decreased pressure gradient and FSS within the collateral vessels, which should have triggered arteriogenesis.

\section{Ranolazine}

Ranolazine reduces the intracellular sodium dependent calcium overload during myocardial ischaemia and thereby prevents electrical instability, reduced contractility and increased diastolic tension. ${ }^{32}$ In patients with $\mathrm{CAD}$, angina frequency and total exercise duration were shown to improve with ranolazine. ${ }^{33}$ However, ranolazine did not reduce adverse cardiovascular events or the angina frequency after incomplete coronary revascularisation. ${ }^{34}$ In this study, ranolazine plus RO came off worse than RO alone. The underlying mechanism is not yet fully understood. However, calcium entry into vascular endothelial cells is known to activate NOS and there is a functional interaction between endothelial sodium-calcium exchange (NCX) and NOS. ${ }^{36}$ Calcium influx through reverse mode NCX is required for VEGF signaling. ${ }^{37}$ From this it can be derived that ranolazine might have impeded the upregulation of NOS and therefore impaired collateralisation.

\section{Candesartan}

Angiotensin II type1 receptor blockers (ARB) are suspected to improve coronary endothelial function by improving the NO bioavailability. ${ }^{38}$ However, the renin-angiotensin system (RAS) with its active peptide Angiotensin II is a major determinant in cardiac remodelling and thus, RAS blockade by candesartan attenuates remodelling. Candesartan was found to inhibit the expression of vascular endothelial growth factor and the proliferation of endothelial progenitor cells. ${ }^{39} 40$ Overall, mode and extent of interaction between ARBs and arteriogenesis, particularly regarding myocardial infarction and cancer, is still controversial. However, the findings from this study of a trend towards worse functional and significantly worse structural outcome with candesartan under the condition of myocardial ischaemia compared with $\mathrm{RO}$ alone confirm the existing knowledge.

\section{Limitations}

The study design did not include the assessment of the treatment effect of cardiovascular drugs in the absence of RO and, therefore, does not permit any final conclusion concerning the efficacy of the studied drugs regarding cardiac resistance against ischaemia and reperfusion. Moreover, arteriogenesis was only indirectly concluded from functional and structural cardiac outcomes after coronary occlusion, but not from comparative imaging of the coronary microvasculature or blood flow measurement. However, the rationale of this study was in accordance with previous findings from a rat model on repetitive occlusion, which included microvascular imaging and blood flow measurement. Infarct size has been reported as a percentage of the left ventricle, not of the anatomic area of risk. Therefore, variation in vascular anatomy had not been taken into account. In humans, CAD and myocardial infarction is an inflammatory condition, and frequently patients suffer from coexisting diseases, which were both not reflected in this rat model.

\section{CONCLUSION}

A sufficiently developed and functioning coronary collateralisation is an important predictor for survival after myocardial infarction in patients with CAD. In this rat model of repetitive myocardial ischaemia, cardiovascular medications turned out to reduce RO-induced myocardial resistance against ischaemia-induced and reperfusion-induced injury, represented by functional and structural cardiac outcome measures. This may have been mainly attributable to a reduced NOS activation by way of a decreased oxygen demand (metoprolol), microvascular vasodilation (verapamil), alteration of endothelial sodium-calcium exchange (ranolazine) or RAS blockade (candesartan). Metoprolol tended to impair cardiac resistance to a less extent, probably, due to its protective, negative inotropic effect. Nitroglycerin did not affect cardiac resistance beyond the level already achieved by repetitive occlusion. However, the experimental setting of this pilot study does not allow for final conclusions regarding the treatment of patients with CAD.

Contributors Substantial contributions to the conception or design of the work: $N G, N G u ̈, P H, A D, F L N, E E B$, IRB; or the acquisition, analysis or interpretation of data for the work: NG, NGü, PH, AD, FLN, EEB, MI, PB, IRB; drafting the work: MI, $\mathrm{PB}$; or revising it critically for important intellectual content: NG, NGü, PH, AD, FLN, EEB, IRB; final approval of the version to be published: all authors; agreement to be accountable for all aspects of the work in ensuring that questions related to the accuracy or integrity of any part of the work are appropriately investigated and resolved: all authors.

Funding The study was funded by a grant from the German Cardiac Society, Düsseldorf, Germany.

Competing interests None declared.

Patient consent Obtained.

Ethics approval The animal procedures were approved by the Regional Office for Health and Social Affairs Berlin (G 0387/10 and G0040/14) and performed according to the guidelines from Directive 2010/63/EU of the European Parliament on the protection of animals used for scientific purposes and the German Animal Welfare Act as amended on May 2006.

Provenance and peer review Not commissioned; externally peer reviewed.

Data sharing statement No additional data are available.

Open access This is an open access article distributed in accordance with the Creative Commons Attribution Non Commercial (CC BY-NC 4.0) license, which permits others to distribute, remix, adapt, build upon this work non-commercially, and license their derivative works on different terms, provided the original work is properly cited, appropriate credit is given, any changes made indicated, and the use is non-commercial. See: http://creativecommons.org/licenses/by-nc/4.0/ 


\section{REFERENCES}

1. Ford ES, Roger VL, Dunlay SM, et al. Challenges of ascertaining national trends in the incidence of coronary heart disease in the United States. J Am Heart Assoc 2014;3:e001097.

2. Meier $P$, Hemingway $H$, Lansky AJ, et al. The impact of the coronary collateral circulation on mortality: a meta-analysis. Eur Heart $J$ 2012;33:614-21.

3. Seiler C, Meier P. Historical aspects and relevance of the human coronary collateral circulation. Curr Cardiol Rev 2014;10:2-16.

4. Kim EK, Choi JH, Song YB, et al. A protective role of early collateral blood flow in patients with ST-segment elevation myocardial infarction. Am Heart J 2016;171:56-63.

5. de Marchi SF, Streuli S, Haefeli P, et al. Determinants of prognostically relevant intracoronary electrocardiogram STsegment shift during coronary balloon occlusion. Am J Cardiol 2012;110:1234-9.

6. Seiler C, Stoller M, Pitt B, et al. The human coronary collateral circulation: development and clinical importance. Eur Heart $J$ 2013;34:2674-82.

7. Hakimzadeh $\mathrm{N}$, Verberne HJ, Siebes $\mathrm{M}$, et al. The future of collateral artery research. Curr Cardiol Rev 2014;10:73-86.

8. Heusch G. Molecular basis of cardioprotection: signal transduction in ischemic pre-, post-, and remote conditioning. Circ Res 2015;116:674-99.

9. Cohen MV, Downey JM. Signalling pathways and mechanisms of protection in pre- and postconditioning: historical perspective and lessons for the future. Br J Pharmacol 2015;172:1913-32.

10. Toyota E, Warltier DC, Brock T, et al. Vascular endothelial growth factor is required for coronary collateral growth in the rat. Circulation 2005;112:2108-13.

11. Murry CE, Jennings RB, Reimer KA. Preconditioning with ischemia: a delay of lethal cell injury in ischemic myocardium. Circulation 1986;74:1124-36.

12. Bainey KR, Armstrong PW. Clinical perspectives on reperfusion injury in acute myocardial infarction. Am Heart J 2014;167:637-45.

13. Jennings RB. Historical perspective on the pathology of myocardial ischemia/reperfusion injury. Circ Res 2013;113:428-38.

14. Hausenloy DJ, Yellon DM. Myocardial ischemia-reperfusion injury: a neglected therapeutic target. J Clin Invest 2013;123:92-100.

15. Yellon DM, Hausenloy DJ. Myocardial reperfusion injury. N Engl J Med 2007;357:1121-35.

16. Raza A, Steinberg K, Tartaglia J, et al. Enhanced external counterpulsation therapy: past, present, and future. Cardiol Rev 2017;25:59-67.

17. Banquet S, Gomez E, Nicol L, et al. Arteriogenic therapy by intramyocardial sustained delivery of a novel growth factor combination prevents chronic heart failure. Circulation 2011;124:1059-69.

18. Meier P, Gloekler S, Zbinden R, et al. Beneficial effect of recruitable collaterals: a 10-year follow-up study in patients with stable coronary artery disease undergoing quantitative collateral measurements. Circulation 2007;116:975-83.

19. Hollander MR, Horrevoets AJ, van Royen N. Cellular and pharmacological targets to induce coronary arteriogenesis. Curr Cardiol Rev 2014;10:29-37.

20. Quebbemann BB, Klassen CL, Bache RJ. Nitroglycerin fails to dilate coronary collateral vessels during exercise. J Cardiovasc Pharmacol 1998;31:821-7.

21. Epstein SE, Lassance-Soares RM, Faber JE, et al. Effects of aging on the collateral circulation, and therapeutic implications. Circulation 2012;125:3211-9.

22. Vogel R, Traupe T, Steiger VS, et al. Physical coronary arteriogenesis: a human "model" of collateral growth promotion. Trends Cardiovasc Med 2010;20:129-33.
23. Billinger M, Raeber L, Seiler C, et al. Coronary collateral perfusion in patients with coronary artery disease: effect of metoprolol. Eur Heart J 2004;25:565-70.

24. Schirmer SH, Degen A, Baumhäkel M, et al. Heart-rate reduction by If-channel inhibition with ivabradine restores collateral artery growth in hypercholesterolemic atherosclerosis. Eur Heart $J$ 2012;33:1223-31.

25. Traverse JH, Altman JD, Kinn J, et al. Effect of beta-adrenergic receptor blockade on blood flow to collateral-dependent myocardium during exercise. Circulation 1995;91:1560-7.

26. Sharifpanah F, Saliu F, Bekhite MM, et al. $\beta$-Adrenergic receptor antagonists inhibit vasculogenesis of embryonic stem cells by downregulation of nitric oxide generation and interference with VEGF signalling. Cell Tissue Res 2014;358:443-52.

27. Sato M, Harding SE, Poole-Wilson PA. Beta-blockers, myocardial ischaemia and collateral circulation. Eur Heart $J$ 2004;25:537-9.

28. Gloekler S, Traupe T, Stoller M, et al. The effect of heart rate reduction by ivabradine on collateral function in patients with chronic stable coronary artery disease. Heart 2014;100:160-6.

29. Remme WJ, Torp-Pedersen C, Cleland JG, et al. Carvedilol protects better against vascular events than metoprolol in heart failure: results from COMET. J Am Coll Cardiol 2007;49:963-71.

30. Kohro T, Hayashi D, Okada Y, et al. Effects of medication on cardiovascular events in the Japanese coronary artery disease (JCAD) study. Circ J 2007;71:1835-40.

31. Liu K, Krone R. Evaluation of coronary steal in myocardium supplied by coronary collaterals: the role of speckle tracking analysis in resting and stress echocardiography. Echocardiography 2013;30:1117

32. Belardinelli L, Shryock JC, Fraser H. Inhibition of the late sodium current as a potential cardioprotective principle: effects of the late sodium current inhibitor ranolazine. Heart 2006;92-iv6-14

33. Chaitman BR, Skettino SL, Parker JO, et al. Anti-ischemic effects and long-term survival during ranolazine monotherapy in patients with chronic severe angina. J Am Coll Cardiol 2004;43:1375-82.

34. Weisz G, Généreux P, Iñiguez A, et al. Ranolazine in patients with incomplete revascularisation after percutaneous coronary intervention (RIVER-PCI): a multicentre, randomised, double-blind, placebo-controlled trial. Lancet 2016;387:136-45.

35. Alexander KP, Weisz G, Prather K, et al. Effects of ranolazine on angina and quality of life after percutaneous coronary intervention with incomplete revascularization: results from the Ranolazine for Incomplete Vessel Revascularization (RIVER-PCI) Trial. Circulation 2016;133:39-47.

36. Teubl M, Groschner K, Kohlwein SD, et al. $\mathrm{Na}(+) / \mathrm{Ca}(2+)$ exchange facilitates $\mathrm{Ca}(2+)$-dependent activation of endothelial nitric-oxide synthase. J Biol Chem 1999;274:29529-35.

37. Andrikopoulos P, Baba A, Matsuda T, et al. Ca2+ influx through reverse mode $\mathrm{Na}+/ \mathrm{Ca} 2+$ exchange is critical for vascular endothelial growth factor-mediated extracellular signal-regulated kinase (ERK) $1 / 2$ activation and angiogenic functions of human endothelial cells. $J$ Biol Chem 2011;286:37919-31.

38. lino $\mathrm{K}$, Watanabe $\mathrm{H}$, lino $\mathrm{T}$, et al. Candesartan improves impaired endothelial function in the human coronary artery. Coron Artery Dis 2012;23:278-83.

39. Jesmin S, Sakuma I, Hattori Y, et al. Role of angiotensin II in altered expression of molecules responsible for coronary matrix remodeling in insulin-resistant diabetic rats. Arterioscler Thromb Vasc Biol 2003;23:2021-6.

40. Ma C, Wang Q, Man Y, et al. Cardiovascular medications in angiogenesis-how to avoid the sting in the tail. Int $J$ Cancer 2012;131:1249-59. 


\section{Correction: cardiovascular drugs attenuated myocardial resistance against ischaemia-induced and reperfusion-induced injury in a rat model of repetitive occlusion}

Gatzke N, Güc N, Hillmeister P, et al. Cardiovascular drugs attenuated myocardial resistance against ischaemia-induced and reperfusion-induced injury in a rat model of repetitive occlusion. Open Heart 2018;5:e000889

The following reference should be included in this article:

41. Gatzke N, Hillmeister P, Dülsner A, et al. Nitroglycerin application and coronary arteriogenesis. PloS One 2018;13:e0201597.

This reference should be cited in two places:

(1) Figure 2 legend (behind NTG, nitroglycerin group):

"Maximal ST-segment elevation (A) and arrhythmias (B) were assessed during $90 \mathrm{~min}$ of final occlusion. Differences between means were compared by Dunett's multiple comparison. Means are pictured as diamonds with their corresponding 95\% CIs (A, C). The Kruskall-Wallis test was used to determine whether proportions of arrhythmia grading differed significantly between each group and sham or ROP. (B). Lown's grading of arrhythmia: $0=$ no ventricular premature beats $(\mathrm{VPB})$, I=unifocal $(1 / \mathrm{min}$ or $\geq 30$ /hour), IIIb=systematised ventricular extra systoles (bigeminy), IVa=2 consecutive beats (couplets), IVb $=\geq 3$ consecutive beats (salvos), $V=R$ on $T$. A value of $p<0.05$ indicated statical significance vs ROP* or vs SGAM**. Number of analysed animals is given in table 1. CAN, candesartan group; MET, metoprolol group; NTG, nitroglycerin group ${ }^{41}$; RAN, ranolazine group; ROP, repetitive occlusion protocol group."

(2) The Discussion section (Nitroglycerin topic, after the first sentence):

"Nitroglycerin is widely administered for rapid coronary vasodilation. ${ }^{41}$ "

(3) Table 1 legend (behind NTG, nitroglycerin group):

*Volume fraction of infarcted myocardium of the left ventricle after sustainedLAD occlusion and reperfusion.

CAN, candesartan group; LAD, left anterior coronary artery; MET, metoprolol group; NTG, nitroglycerin group ${ }^{41}$.

Open access This is an open access article distributed in accordance with the Creative Commons Attribution Non Commercial (CC BY-NC 4.0) license, which permits others to distribute, remix, adapt, build upon this work non-commercially, and license their derivative works on different terms, provided the original work is properly cited, appropriate credit is given, any changes made indicated, and the use is non-commercial. See: http://creativecommons.org/licenses/by-nc/4.0

(C) Author(s) (or their employer(s)) 2019. Re-use permitted under CC BY-NC. No commercial re-use. See rights and permissions. Published by BMJ.

Open Heart 2019;6:e000889corr1. doi:10.1136/openhrt-2018-000889corr1

Check for updates 